\title{
Designing to Include Judges and Inner-City Tenants
}

\author{
Kathryn Summers ${ }^{1 *}$, Amy Pointer ${ }^{1}$, Michele Cotton ${ }^{1}$, \\ ${ }^{1}$ University of Baltimore, Baltimore, MD, USA \\ \{ksummers@ubalt.edu, apointer@ubalt.edu, mcotton\}@ubalt.edu
}

\begin{abstract}
Between 2012 and 2015, an analysis of more than 300 rent escrow cases in the city of Baltimore revealed that neither judges nor plaintiffs in rent escrow cases understood or were correctly applying the relevant laws [1], [2]. Tenants didn't understand the applicable laws or available remedies, and were unable to fill out their rent escrow applications accurately. Judges knew that the documents provided by tenants were probably filled out incorrectly, so they routinely ignored these documents. Thus, many rent escrow cases were decided based on established custom rather than on the facts of the case or relevant laws, and the results tended to favor landlords [1], [3]. A year of iterative design, testing, and re-design resulted in a rent escrow form that could 1) help tenants understand their options and provide accurate information to the court, and 2) provide judges with accurate information while simultaneously reinforcing their understanding of the applicable laws.
\end{abstract}

Keywords: Low Literacy · Legal forms · Inclusive design · Plain language

\section{Introduction}

The difficulties faced in court by low-income, unrepresented litigants are well documented [4], [5], [6]. Although legal representation can improve outcomes for lowincome litigants, increasing the extent of legal representation is costly not only in terms of requiring more time from lawyers but also because greater involvement by lawyers is likely to increase the number of cases that come to court as well as the amount of time the court spends on individual cases [1]. Most jurisdictions are well aware of these costs, and thus efforts to dramatically increase the rate of representation in court for low-income litigants have not historically been successful, and are not likely to be successful in the future [1].

Starting in 2012, Michele Cotton supervised a research project that pulled more than 300 rent escrow cases filed between 2011 and 2012 from the records of the Baltimore City District Court. Cases were selected randomly, then retained for inclusion in the study if at least one litigant in the case was unrepresented and the record included at least one appearance before a judge.

\footnotetext{
* Support for this study was provided by C. Matthew Hill of the Public Justice Center, Sarah Frush of Maryland Legal Aid, the University of Baltimore, and the Center for Civic Design.
} 
Careful analysis of these cases showed that tenants rarely received the monetary relief to which they appeared to be entitled under the law (even when serious violations of housing codes were both documented and unresolved), and judges often did not fully investigate the facts of the case and rarely made formal "findings of fact." Moreover, tenants were frequently deprived of due process of law because their attempts to get housing conditions improved were often dependent on their ability to deposit full escrow amounts with the court, before the court had actually examined the case to see if full rent was in fact owed [1].

Based on this study, a Baltimore City judge convened a rent escrow committee in 2015 to explore remedies - bringing together a variety of stakeholders including judges, law clerks, lawyers, landlord agents, and tenant advocates. This committee met once a month for nearly two years.

One remedy proposed by members of this committee was to redesign the form used by tenants to apply for rent escrow in order to serve two purposes: 1) help tenants understand their options and provide accurate information to the court, and 2) provide judges with accurate information while simultaneously reinforcing their understanding of the applicable laws. ${ }^{2}$

Legal "realists" such as Howard Erlanger and his colleagues suggest that improvement to the functioning of our legal system is best achieved by "remaining cognizant of hierarchies of power and the paradoxes they create for law" but by also "asking what can be done to work toward justice within the existing structures" [7]. In particular, David Super advocates improving the process of applying the law in ways that support correct application of the law-and, if possible, make it easier and quicker to apply the law correctly [8].

The design project described in this paper illustrates the reality that sometimes designing for inclusion means designing for multiple, very different audiences. The redesigned form needed to meet very specific needs in order to serve the needs of both the low-income tenants and the well-educated, experienced, but also consistently overworked judges. Many inner-city tenants in Baltimore have low literacy skills and limited educational attainment [9], and may have limited or even faulty knowledge of their rights under the law. At the same time, judges in Baltimore City have heavy case loads, do not have much time or incentive to pursue relevant factual information for individual cases, do not have much guidance on warranty of habitability law from appellate courts, and have mostly been dependent on their individual interpretations of the relevant law for case decisions [1].

\footnotetext{
${ }^{2}$ Some research suggests that using less usable forms is occasionally a deliberate strategy to reduce judicial caseloads. In Detroit, when the court experimented with "plain English" forms, the simpler forms led to an increased number of tenant claims, and the court subsequently reverted to legalese [10], [8]. Thus, there is a potential for opposition to improved forms to be driven by concerns about limited court resources [11].
} 


\section{Methods}

The project to redesign the form was interdisciplinary and iterative, involving six major stages before the form could be deployed:

1. Graduate students in Legal and Ethical Studies at the University of Baltimore gathered and analyzed more than 300 rent escrow case histories to examine outcomes and identify possible failures to follow the relevant law.

2. The next phase was developing content specifications for the redesigned form. Based on these case studies, a partnership of lawyers and academics identified the legal information that the form would need to elicit from tenants in order to provide proper support for their rent escrow cases—-such as a full list of the potential housing code violations, the date of first notice to the landlord, and the type of notice given - and information about the range of remedies tenants could request under the law. The team also identified key information needed by judges in order to properly apply the warranty of habitability law in Maryland.

3. Based on the specifications, University of Baltimore faculty with expertise in usable design and user research then began a process of iterative design of the form to make it understandable and usable. The form was tested for clarity and usability with residents of Baltimore possessing low literacy skills during five rounds of testing over five months. Several of these rounds also incorporated changes to the form requested by lawyers on the Baltimore City rent escrow committee.

4. Once the design of the form had stabilized, legal and administrative vetting of the form began in earnest. The rent escrow committee reviewed the form several times, requesting several additions and clarifications to provide greater support to the judges who might potentially use the form. Baltimore city judges were asked to consider the form for potential adoption by the courts. This process lasted several months, and resulted in additional requested changes. The Access to Justice Department of the State of Maryland and the Forms Committee of the Court agreed to consider the form for adoption - and in fact decided to consider it for deployment throughout the state.

5. Before the revised form was submitted for these final reviews, the form was again tested with participants with low literacy skills. Unfortunately, the changes had again made the form unusable for this audience, so the design and research team renewed their testing and iterative revision of the form.

6. The final form is expected to be approved for deployment across Maryland in 2017. The reception of the form was sufficiently positive that the team hopes to be invited to revise other legal forms in the state.

\subsection{Participants}

Testing involved 38 participants in eight rounds of testing. Participants were drawn from inner-city Baltimore, and qualified as having low literacy skills, i.e., reading at 
the eighth grade level or below as measured by the Rapid Estimate of Adult Literacy in Medicine (REALM) [12]. ${ }^{3}$

Direct testing of the form with judges was not feasible, but the courts and the legal community had multiple opportunities to review the form over the course of the project and requested a variety of changes and accommodations.

Previous research has indicated that - other factors remaining constant-making forms easier to use for participants with low literacy skills tends to increase usability for high literacy audiences as well [13].

\section{$2.2 \quad$ Testing Logistics}

Tests took place in the User Research Lab of the University of Baltimore. Participants filled out a version of the paper form, sitting at a table with the user researcher. The visual designer - who specializes in creating usable design - watched from behind a one-way mirror, with added visibility provided by a close-up video camera feed of the form.

After the participant filled out the form, the user researcher went through the questions on the form with the participant. Areas where the participant had missed a question or misunderstood a question were noted. Places where the form had not elicited all of the relevant information on an issue were also noted.

\section{Results \& Discussion}

In a narrow sense, the product of this research was the revised form itself. Viewed more broadly, the research effort also provided insights into necessary and effective processes for improving the usability of public documents that must address multiple audiences and needs.

\subsection{Getting the content right}

The first step was to identify the legal information needed in the revised rent escrow application. The form needed to educate tenants about their rights and about the range

\footnotetext{
${ }^{3}$ The REALM is one of several possible instruments for estimating adult literacy levels. It is comprised of a list of 66 words that a participant reads aloud as a facilitator keeps score of words pronounced correctly; the score is the number of correct words a participant pronounces. Although originally designed to measure health literacy, REALM has several advantages for field work-primarily in that it takes 2-5 minutes, requires minimal training to administer, and does not feel like a literacy test to participants. The REALM has been shown to reliably distinguish between adults at lower literacy levels [14], although it does not distinguish between adults at a $9^{\text {th }}$ grade reading level or above. The REALM is also highly correlated with the Wide Range Achievement Test-Revised $(\mathrm{r}=0.88)$, the revised Slosson Oral Reading Tests $(\mathrm{r}=0.96)$, the revised Peabody Individual Achievement Test $(\mathrm{r}=0.97$, and the TOFHLA $(\mathrm{r}=0.84)$ [15], [16]. The REALM also has a high test-retest reliability $(\mathrm{r}=0.97)$ [12].
} 
of possible remedies available to them. It also needed to collect the information from tenants that was necessary in order to support their claim, such as the date of first notice to landlords about violations.

At the same time, the form also needed to indirectly remind/inform judges and law clerks about the rights of tenants and the remedies available to them under the warranty of habitability law in Maryland. It needed to make the information provided by tenants easily accessible to judges so that judges could easily and quickly grasp the range and potential severity of the alleged housing code violations, making this information more likely to be considered in court. The form also served as an indirect reminder to judges about the range of acceptable forms of notice from tenants to landlords about violations as well as the range of remedies supported by the law.

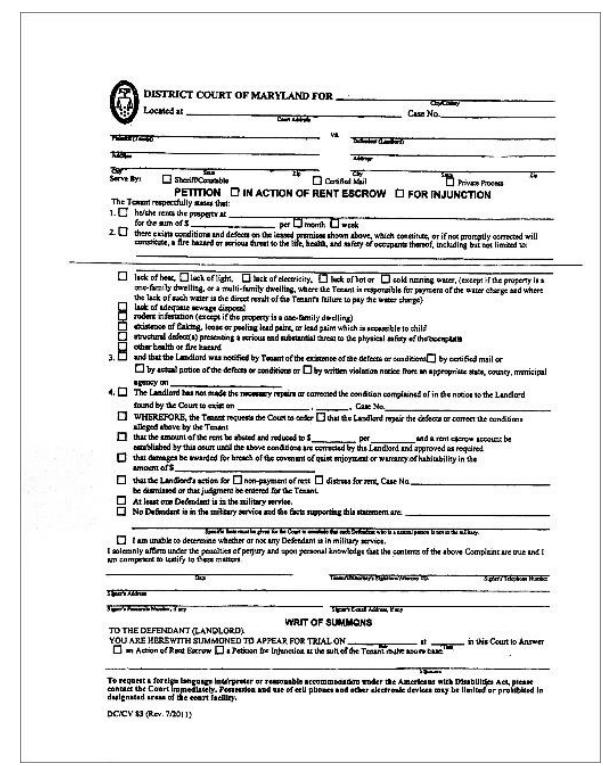

Fig. 1. This original rent escrow application form uses legal terms that are unlikely to be familiar to most Baltimore City tenants. It has large amounts of unnecessary and complex text and is visually dense. It provides no visual guidance as to which elements of the form should be considered as a group. The form is hard to fill out, and this problem is compounded by the fact that once filled out, the completed form is equally hard to decipher for judges.

\subsection{Making the form usable for plaintiffs}

Unfortunately, when the content-based revision was completed, the form turned out to be almost completely unusable for inner-city tenants, many of whom read at the 8th grade level or below (as do 43\% of adults in the U.S. [17]). In order to create a successful form, the revision process needed to include simpler language, a cleaner typeface (sans serif), and improved interaction cues through visual design.

The first step was to strip out unnecessary verbiage and to simplify the language, removing confusing legal terms such as "actual notice," "covenant of quiet enjoyment," and "warranty of habitability." The next step was to adjust the order of the 
questions to feel logical from the tenant's point of view. Any references in one question to information contained in another question were removed, to accommodate the needs of tenants with low literacy skills for linear processing and minimal reliance on working memory [18], [19].

The principles guiding the visual redesign included providing white space, or "breathing space," between each conceptual element of the form. Clear spatial "pauses" between steps is a way to reinforce the user's sense of progress and provide a brief natural resting point between the effort of answering each question. At the same time, strategic use of white space makes the form look easier to use, and can signal grouping and information hierarchy. The layout was designed on a grid, using vertical alignment and line length to create visual blocks where appropriate, and space was transferred from the header and footer to the main area of the form, since this was the most challenging section to complete correctly.

Research has shown that increasing text size can also make text and forms easier to process for people with low literacy skills. Unfortunately, as the amount of required text and form elements grew (each level of legal and judicial review necessitated changes and additions), the text size became smaller than was optimal. Fortunately, the clear information hierarchy and judicious use of breathing space was able to compensate sufficiently for the smaller text that the form remained usable for tenants (as long as they have access to reading glasses, if needed).

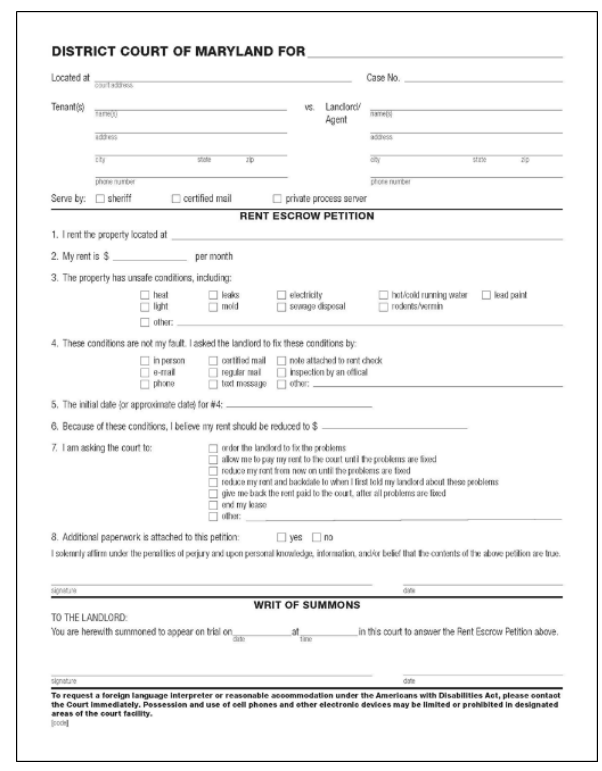


Fig. 2. The first draft of the revised form was much more clean and inviting, and once filled out as if by a tenant, was much easier to decipher.

\subsection{Keeping the form usable for plaintiffs while meeting the needs of judges and law clerks}

Design for inclusion in the legal and judicial sphere must be an interdisciplinary endeavor - combining the skills of lawyers, legal experts, designers, and user researchers. The process of iterative design and redesign required collaboration between tenant advocates, lawyers, designers, user researchers, court clerks, and judges. The form was progressively reviewed by legal aid advocates, then by the rent escrow committee, then by the Baltimore City Circuit Court judges. At every stage, additions and changes to the form were requested.

As would be expected, these changes repeatedly made the form more complex or more crowded, reducing - and occasionally destroying - the form's usability for the inner-city tenants who needed to fill it out. Visual and textual redesign of the form based on continued user testing with potential tenants at each stage of court review was crucial. By the time the form was final, it had gone through 18 versions, eight rounds of testing, and 38 participants.

\subsection{Getting approval from the courts}

No matter how useful and usable the final form turned out to be, the project would be wasted unless the City of Baltimore could be persuaded to adopt the new form.

This part of the process involved months of effort, including numerous meetings. At every stage, requests for revisions were received - requiring redesign and re-testing to discover whether incorporation of changes had successfully preserved usability of the form for low-literacy users. If changes had made the form unusable, additional negotiation between the design team and the legal stakeholders and iterative testing and design ensued.

Final success ultimately depended on persuading a high-level judge to drive the adoption process. 


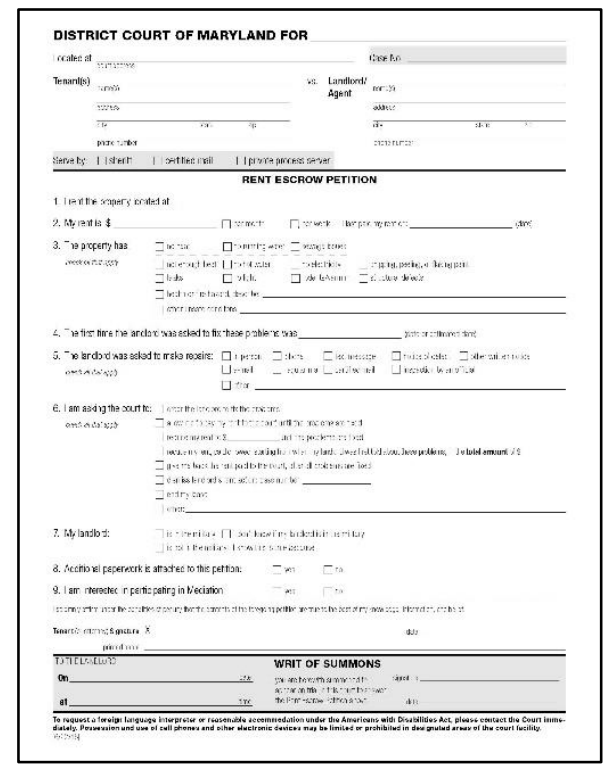

Fig. 3. The final version of the form is more complex than the initial revised draft, with added fields and questions. The text size has diminished. But the clear visual hierarchy and generous white space continue to support successful use.

\section{Conclusion}

The final design was recently approved by the State of Maryland's Access to Justice Department, and it is expected that it will soon be approved by the Committee of the Court responsible for legal forms. The State of Maryland plans to deploy the new form across the entire state. The demonstrable success of combining legal clarity with truly inclusive design through a process of iterative design and user testing means that the team is likely to be invited to revise other state forms and processes.

Lessons learned:

- When evidence is discovered that the legal system is not working properly, it is common to seek broad systemic remedies. However, in some cases the potential solutions may be simpler - and less costly - than this. Designing processes and forms for usability is one of the tools that can be deployed in these situations.

- Poor design of official court documents can present barriers to proper use of these forms not only by members of the public (including those with low literacy), but also by highly educated legal professionals such as judges.

- Such barriers can include unnecessary verbiage, overly complex legal language, poor information hierarchy, visual design that makes it hard to identify key information, and a failure to support linear processing. Truly inclusive design can address these issues by guiding the design of court documents 
that will meet the needs of highly educated judges as well as the general public.

- The goals of legal completeness and usability exert potentially conflicting influences on design decisions, making testing and re-testing essential throughout the redesign process.

- Quantitative evidence of the problem to be solved can lead to buy-in across a broad array of stakeholders. Without widespread evidence of potential miscarriages of justice, it seems unlikely that stakeholders would have been so willing to consider changes to court procedures, particularly in light of the effort involved.

Acknowledgments. Partial funding for this project was provided by the University of Baltimore and by the Center for Civic Design. Support was also provided by Sarah Frush of Maryland Legal Aid and C. Matthew Hill from the Public Justice Center.

\section{References}

1. Cotton, M.: When Judges Don't Follow the Law: Research and Recommendations. CUNY L. Rev., 19, 57 (2015)

2. Center, P. J.: Justice Diverted: How Renters Are Processed in the Baltimore City Rent Court (2015)

3. Bezdek, B.: Silence in the Court: Participation and Subordination of Poor Tenants' Voices in Legal Process. Hofstra Law Review, 20, 533 (1992)

4. Seron, C., Frankel, M., Van Ryzin, G., \& Kovath, J. The impact of legal counsel on outcomes for poor tenants in New York City's housing court: results of a randomized experiment. Law and Society Review, 419-434 (2001)

5. Hannaford-Agor, P., \& Mott, N. Research on self-represented litigation: preliminary results and methodological considerations. Justice System Journal, 24(2), 163-181 (2003)

6. Sandefur, R. L. The Impact of Counsel: An Analysis of Empirical Evidence. Seattle J. Soc. Just., 9, 51 (2010)

7. Erlanger, H., Garth, B., Larson, J., Mertz, E. Nourse, V., \& Wilkins, D.: New Legal Realism Symposium: Is it time for a new legal realism? Wis. L. Rev., 335 (2005)

8. Super, D. A.: The rise and fall of the implied warranty of habitability. California Law Review, 389-463 (2011)

9. U.S. Department of Education, Institute of Education Sciences, National Center for Education Statistics, 2003 National Assessment of Adult Literacy, https://nces.ed.gov/naal/estimates/StateEstimates.aspx

10. Rose, J. I., \& Scott, M. A. "Street Talk" Summonses in Detroit's Landlord-Tenant Court: A Small Step Forward for Urban Tenants. J. Urb. L., 52, 967 (1974)

11. Cotton, M. A Case Study on Access to Justice and How to Improve It. JL Soc'y, 16, 61 (2014)

12. Davis, T.C., Long, S.W., Jackson, R.H., Mayeaux, E.J., George, R.B., Murphy, P.W., Crouch, M.A. Rapid estimate of adult literacy in medicine: a shortened screening instrument. Fam. Med. 25, 391-395 (1993).

13. Summers, K., \& Summers, M.: Reading and navigational strategies of web users with lower literacy skills. Proceedings of the American Society for Information Science and Technology, 42(1) (2005)

14. Alqudah, M., Johnson, M., Cowin, L., George, A.: Measuring health literacy in emergency departments. J. Nurs. Educ. Prac. 4, 1-10 (2014). 
15. Davis, T.C., Kennen, E. M., Gazmararian, J.A., Williams, M.V.: Literacy testing in health care research. In: Schwartzberg, J.G., VanGeest, J.B., Wang, C.C. (eds.) Understanding health literacy: implications for medicine and public health, pp. 157-179. American Medical Association, Chicago (2005).

16. Parker, R.M., Baker, D.W., Williams, M.V., Nurss, J.R.: The test of functional health literacy in adults: a new instrument for measuring patients' literacy skills. J. Gen. Intern. Med. 10, 537-541 (1995).

17. Kutner, M., Greenberg, E., Jin, Y., Boyle, B., Hsu, Y., Dunleavy, E.: Literacy in everyday life: results from the 2003 National Assessment of Adult Literacy. NCES 2007-490. National Center for Education Statistics, Washington, DC (2007).

18. Summers, K., Langford, J., Wu, J., Abela, C., \& Souza, R.: Designing Web-based Forms for Users with Lower Literacy Skills. Proceedings of the American Society for Information Science and Technology, 43(1), 1-12 (2006)

19. Summers, K., \& Langford, J.: The Impact of Literacy on Usable and Accessible Electronic Voting. In International Conference on Universal Access in Human-Computer Interaction (pp. 248-257). Springer International Publishing (2015) 